\title{
ANÁLISE DA PERCEPÇÃO AMBIENTAL COMO SUBSíDIO À GESTÃO NO MUNICÍPIO DE PARACURU - CE
}

\author{
Cristiano da Silva Rocha \\ Universidade Estadual do Ceará (UECE) \\ Programa de Pós-Graduação, Fortaleza, CE, Brasil \\ crisbandeiras@hotmail.com \\ Fábio Perdigão Vasconcelos \\ Universidade Estadual do Ceará (UECE) \\ Programa de Pós-Graduação, Fortaleza, CE, Brasil \\ fabioperdigao@gmail.com \\ Maria Bonfim Casemiro \\ Universidade Estadual do Ceará (UECE) \\ Programa de Pós-Graduação, Fortaleza, CE, Brasil \\ mariabonfimc@gmail.com \\ Maryane Andrade Ribeiro \\ Universidade Estadual do Ceará (UECE) \\ Programa de Pós-Graduação, Fortaleza, CE, Brasil \\ maryandrade90@hotmail.com \\ Otávio Augusto de Oliveira Lima Barra \\ Universidade Estadual do Ceará (UECE) \\ Programa de Pós-Graduação, Fortaleza, CE, Brasil \\ otavioaolbarra@gmail.com
}

\begin{abstract}
RESUMO
A percepção ambiental consiste numa forma de se analisar os problemas ambientais a partir da visão cognitiva dos atores sociais envolvidos, procurando perpassar a mera observação mecanicista e assistemática das questões ambientais. Diante disso, o artigo tem como objetivo geral avaliar a percepção ambiental e suas contribuições para a gestão do município de Paracuru, Ceará. Baseando-se na metodologia proposta por Minayo et al. (2005), foram aplicados 100 questionários relacionados ao universo de 8770 domicílios ocupados de forma permanente. O mesmo procedimento foi executado com a gestão ambiental do município. Os resultados apontaram que, de maneira geral, os agentes reconhecem problemas ambientais e a vulnerabilidade dos ambientes. Por outro lado, os gestores acrescentam como problemas a pressão por carcinicultura ilegal, falta de incentivo à fiscalização ambiental, bem como o cumprimento precário dos critérios para o município licenciar. Além disso, comprovou-se a imprescindível necessidade da participação popular na fiscalização e cobrança das melhorias sociais e ambientais.
\end{abstract}

Palavras-chave: Cognitivo Ambiental. População. Gestores. Zona costeira. Paracuru.

\section{ANALYSIS OF ENVIRONMENTAL PERCEPTION AS A SUBSIDY TO MANAGEMENT IN THE COUNTY OF PARACURU - CE}

\begin{abstract}
Environmental perception is a way of analyzing environmental problems from the cognitive view of the social actors involved, seeking to permeate the mere mechanistic and unsystematic observation of environmental issues. In light of this, this paper has as its main goal evaluate the environmental perception and its contributions to the management of the municipality of Paracuru, Ceará. Based on the methodology proposed by Minayo et al. (2005), 100 questionnaires related to the universe of 8770 households occupied permanently were applied. The same procedure was carried out with the county's environmental management. The results showed that, in general, the agents recognize environmental problems and the vulnerability of the environments. On the other hand, the managers add as problems the pressure for illegal shrimp farming, lack of incentive to environmental inspection, as well as the precarious fulfillment of the criteria for the county to license. Besides that, it proved the essential need for popular participation in the inspection and charge of social and environmental improvements.
\end{abstract}

Keywords: Environmental Cognitive. Population. Managers. Coastal zone. Paracuru.

Caminhos de Geografia $\quad$ Uberlândia $\quad$ v. 22, n. $84 \quad$ dez/2021 $\quad$ p. 101-118 $\quad$ Página 101




\section{INTRODUÇÃO}

A percepção enquanto aplicação em estudos geográficos tem início na década 60 , com geógrafos norteamericanos, em trabalhos que buscavam entender a percepção de risco para o problema da população que retornava a locais suscetíveis (Souza \& Zanella, 2009). A análise dos problemas ambientais a partir da percepção ambiental não é exclusiva deste escrito, tendo sido destacada nos trabalhos de Rossoni et al. (2012) e Schiavinato \& González (2020); ambos engajados no despertar de uma gestão participativa. A participação destacada centra-se em uma abordagem denominada "percepção", e, neste caso ambiental, de acordo com Palma (2005), entender a percepção dos atores sociais é importante para captar as interrelações deles com o ambiente e as possíveis tomadas de decisões.

Neste sentido, o objetivo deste trabalho é avaliar a percepção ambiental e suas contribuições para a gestão do município de Paracuru, Ceará. Para isso, foram aplicados questionários e entrevistas (Minayo et al., 2005), que contribuíram para identificação de problemas ambientais e possíveis soluções e percepção de ambientes vulneráveis. A vulnerabilidade socioambiental, bem como a suscetibilidade a processos erosivos em Paracuru foram detalhados em pesquisa de Mestrado.

Neste contexto, os problemas que contribuem para vulnerabilidade do ambiente podem estar relacionados ao crescimento e concentração populacional, a condições sociais; carência de infraestruturas; insuficiência de recursos e de marcos regulatórios, como também a degradação dos ecossistemas; erosão dos solos ou processos erosivos contínuos; acumulação de dejetos e os diversos tipos de poluição e contaminação (Cepal; Santos, Câmara, 2002). Acrescenta-se a esses, o fato de existir grande diversidade de sistemas ambientais em Paracuru elencados por Souza et al. (2002), são eles: praias, cordões litorâneos, dunas, planície fluviomarinha, falésias, tabuleiro e depressão sertaneja. Assim, principalmente os ambientes costeiros exibem maior vulnerabilidade (Rocha, 2020), pois são altamente requisitados pela ocupação e são apontados como ambientes com fortes morfogênese (Tricart, 1977).

Diante do cenário, os interesses e conflitos em muitos municípios costeiros, as atividades tradicionais dão lugar a outras formas produtivas. Os novos usos e empreendimentos de alto poder aquisitivo ganham prerrogativas na instalação, e em muitos casos comprometem o uso para outras atividades. $E$ neste contexto contribuir para o envolvimento das comunidades locais na gestão é forma de atingir objetivos conservacionistas e conscientizar a população sobre a sustentabilidade (Paula et al., 2014). O não envolvimento pode contribuir para a desinformação, o que torna a comunidade alheia aos processos decisórios e pode interferir na sua existência.

De maneira geral, a percepção é uma forma de dar voz aos atores sociais e de entender que os trabalhos que utilizam a percepção ambiental têm por objetivo não só a relação homem e meio natural, como também que o conceito esteja presente em pesquisas científicas, sociais ou políticas (Pacheco \& Silva, 2006). A maneira como o morador e o gestor enxergam é parte do que vivenciam de maneira mais íntima com os problemas e fatores positivos ao bem estar.

Quando o indivíduo é questionado, as emoções e o cognitivo o fazem refletir sobre a resposta, e é nesse momento que o mesmo revela sua identidade com o local e passa a refletir sobre o todo (Macedo, 2000). Sendo assim, espera-se que se sobreponha a racionalidade no trato com os recursos naturais, a partir do despertar que é possibilitado pela percepção (Whyte, 1978).

A pesquisa comprovou a hipótese de que parcela da população percebem os problemas ambientais que os cercam e a suscetibilidade dos ambientes, indicando ainda maior necessidade de diálogo entre os atores que compõem a gestão, sejam moradores de qualquer localidade e/ou gestores de esferas diferentes. No município estão delimitadas 3 unidades de proteção estaduais, quais sejam a área de proteção ambiental do estuário do Rio Curu, área de proteção ambiental das Dunas de Paracuru e a mais recente área de proteção ambiental das Dunas do Litoral Oeste, que abrange os municípios de Paracuru e São Gonçalo do Amarante (Rocha, 2020).

O município atende os critérios do Decreto N. 140 de 2011, e por isso tem competência de fiscalizar e licenciar seu território com exceção das Unidades de Proteção Ambiental, que são gerenciadas pela Secretaria de Meio Ambiente no caso da APA do estuário do Rio Curu e das Dunas de Paracuru, e no caso da APA das Dunas do Litoral Oeste a gestão é feita pela Superintendência Estadual do Meio Ambiente (SEMACE), em parceria com um comitê gestor com diversos representantes. Desta forma, é possível afirmar que a gestão ambiental em Paracuru é compartilhada.

A participação local por meio das respostas é uma maneira de perceber a paisagem (Medeiros et al., 2014), sua dinâmica e os interesses que contrastam com os interesses dos moradores. Entender quais os

$\begin{array}{llllll}\text { Caminhos de Geografia } & \text { Uberlândia - MG } & \text { v. 22, n. } 84 & \text { dez/2021 } & \text { p. 101-118 } & \text { Página } 102\end{array}$


Análise da percepção ambiental como subsídio à gestão no município de Paracuru - CE
Cristiano da Silva Rocha

Fábio Perdigão Vasconcelos

Maria Bonfim Casemiro

Maryane Andrade Ribeiro

Otávio A. de Oliveira Lima Barra

problemas e as formas de contribuição da população para solucionar os mesmos e ainda discutir quais os caminhos para a sustentabilidade a partir da qualidade da paisagem e do ambiente (Fernandes e Sansolo, 2013).

\section{Área de estudo}

A área de estudo é o município de Paracuru, que exibe grande diversidade de ambientes, apresenta sua sede a cerca de 200 metros da praia e foi recentemente incorporado a Região Metropolitana de Fortaleza

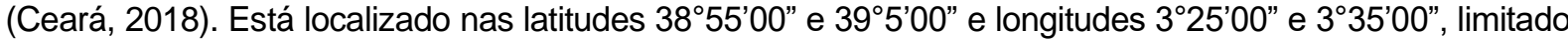
ao norte pelo município de Paraipaba, ao oeste e sul por São Gonçalo do Amarante e a leste pelo oceano atlântico (Mapa 1).

Mapa 1 - Mapa da área de estudo

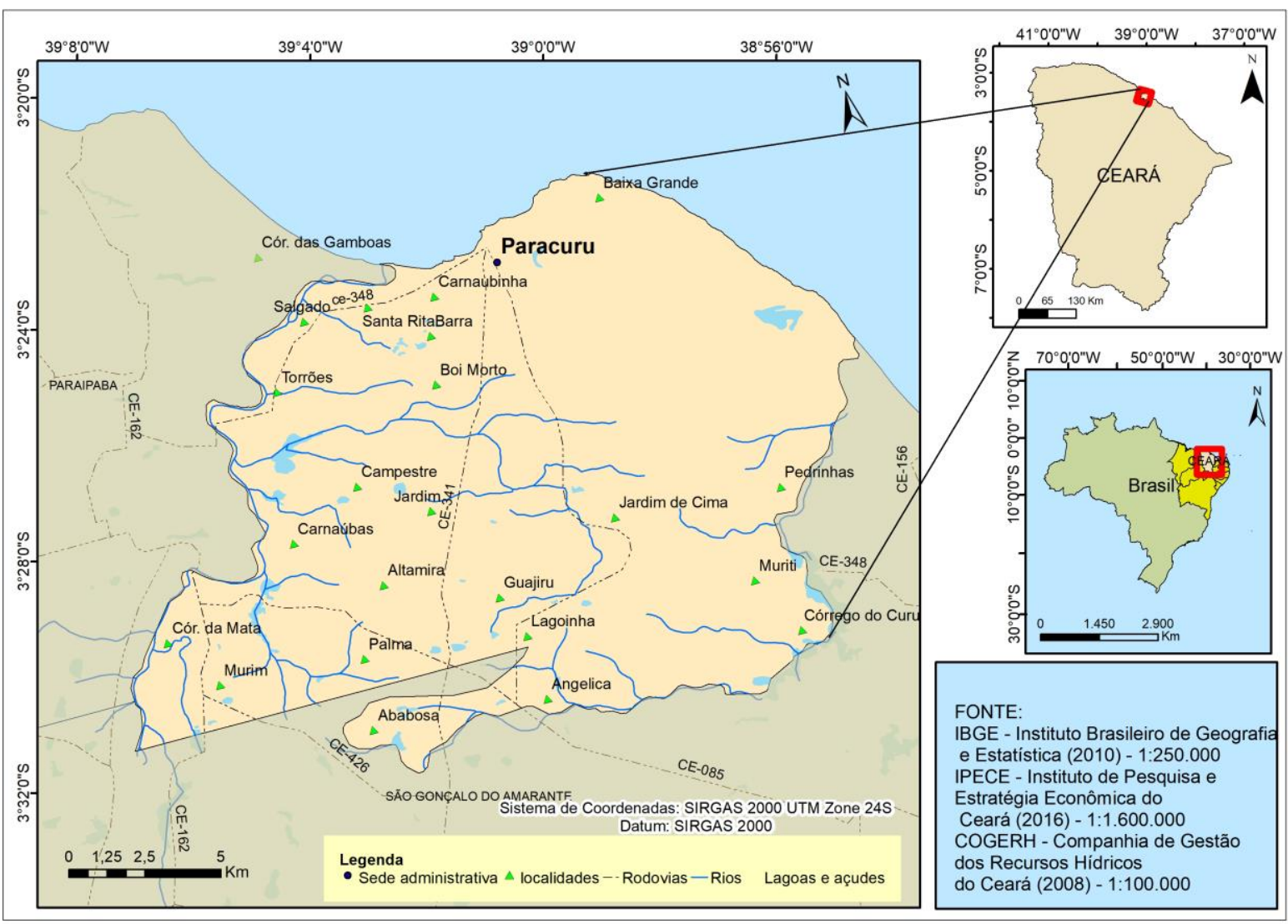

Fonte: Autores (2020).

Segundo o relatório final de mapeamento e potencialidade de uso, elaborado pela Superintendência Estadual do Meio Ambiente (SEMACE), são características fortes do município de Paracuru sua área de aproximadamente $304,286 \mathrm{~km}^{2}$, tendo densidade demográfica de $110 \mathrm{hab} / \mathrm{km}^{2}$; número que aumenta de maneira intensa nos períodos festivos e na alta estação do turismo (Ceará, 2016).

Em 2010, de acordo com o Instituto Brasileiro de Geografia e Estatística (IBGE), a população era 31.636 pessoas e estava distribuída em relação as atividades econômicas em agropecuária (15,34\%), indústria (32,09\%), serviços (52,57\%) (Cavalcante et al., 2017). Ainda segundo os dados do instituto, em 2020, estima-se que o município de Paracuru possui 35.304 habitantes (IBGE, 2020).

\section{METODOLOGIA}

Inicialmente, foi elaborado um questionário utilizando os conhecimentos adquiridos a partir das leituras de Minayo et al. (2005). Os questionários compõem uma abordagem oriunda da sociologia (Minayo, 1992), de forma que as respostas possibilitem uma representação de dados - gráficos e tabelas - expressando

$\begin{array}{llllll}\text { Caminhos de Geografia } & \text { Uberlândia - MG } & \text { v. 22, n. } 84 & \text { dez/2021 } & \text { p. 101-118 } & \text { Página } 103\end{array}$


os resultados em números de maneira proposta. Esta pesquisa foi aprovada pelo Comitê de Ética em Pesquisa da UECE e registrada na Plataforma Brasil sob o número 99597218.6.0000.5534.

Neste contexto, foi necessário identificar o valor do erro diante de um número de questionários prévio. 0 número do erro foi estabelecido conforme a fórmula que consta na figura 1, e levou em consideração o número de domicílios ocupados de forma permanente, conforme dados do Censo do IBGE (2010). Considera-se que cada domicílio permanente abriga uma ou mais famílias.

O número de questionários foi determinado com base no teste de erro, e observou-se que para o valor de 100 questionários, como amostra do erro, é de aproximadamente 9\% (Levine et. al., 2000).

Figura 1 - Fórmula usada para calcular o erro

$$
n=\frac{Z^{2} \times p \times q \times N}{d^{2} \times(N-1)+\left(Z^{2} \times p \times q\right)}
$$

Fonte: Levine et al. (2000).

Onde,

$\mathrm{n}$ = tamanho da amostra (100 questionários estabelecidos);

$\mathrm{N}=$ Universo (8770 domicílios particulares permanentes);

p e q = Número de elementos favoráveis e desfavoráveis da amostra preestabelecidos em 0,5;

$Z$ = Nível de confiança preestabelecido em 1,96 (valor relacionado a 95\% de confiança);

$\mathrm{D}=$ Porcentagem de erro (encontrado valor $9 \%$ de erro).

Foi estabelecido o tamanho da amostra de 100 questionários relacionados ao universo de 8770 domicílios, além das variáveis p e q 0,5, e 1,96 para confiança de $95 \%$, obtendo-se o erro de $9 \%$.

Embora os dados gerem resultados em expressão matemática, a investigação qualitativa se dedica a entender o universo dos significados e a informação que não pode ser quantificada. A proposta possui como objeto de investigação a percepção, e, embora existam limitações espaciais, a pesquisa foi realizada em pontos e vias de maior circulação em um dia de semana ou pelo menos um dia de final de semana.

A proposta foi centrada em discutir a realidade da experiência dos moradores em relação a temas previamente abordados no escopo do trabalho, para isso foi elaborado o questionário seguindo orientações de Hill \& Hill (1998). Esta proposta tem inspiração no exemplo do estudo da percepção das condições de vida dos moradores de um determinado bairro ou de uma favela, e na possibilidade de despertar uma consciência crítica (Minayo, 1992).

Chaer et al. (2011) explica que a aplicação de questionários é uma técnica para obter informações com a população, garantindo padronização dos dados no excel, que serão obtidos de maneira aleatória em um espaço previamente determinado.

A aplicação de questionário e entrevistas foi realizada entre os dias 19 e 20 de julho de 2019. Julho foi realizada a maior parte dos questionários, restando apenas 7 para 0 mês de dezembro, em que foi realizada a entrevista também com os gestores, dia 15 de dezembro (Secretário de Meio Ambiente) e 18 de dezembro (Gestores da APA e da SEMA).

A distribuição dos questionários está relacionada aos setores Paracuru Sede, Poço Doce e Jardins 69, na sede urbana, divididos em 6 pontos de aplicação em casas aleatórias, onde 31 são na zona rural, divididos em 17 para o distrito de Poço Doce e 14 para o Distrito de Jardim (Gráfico 1). 


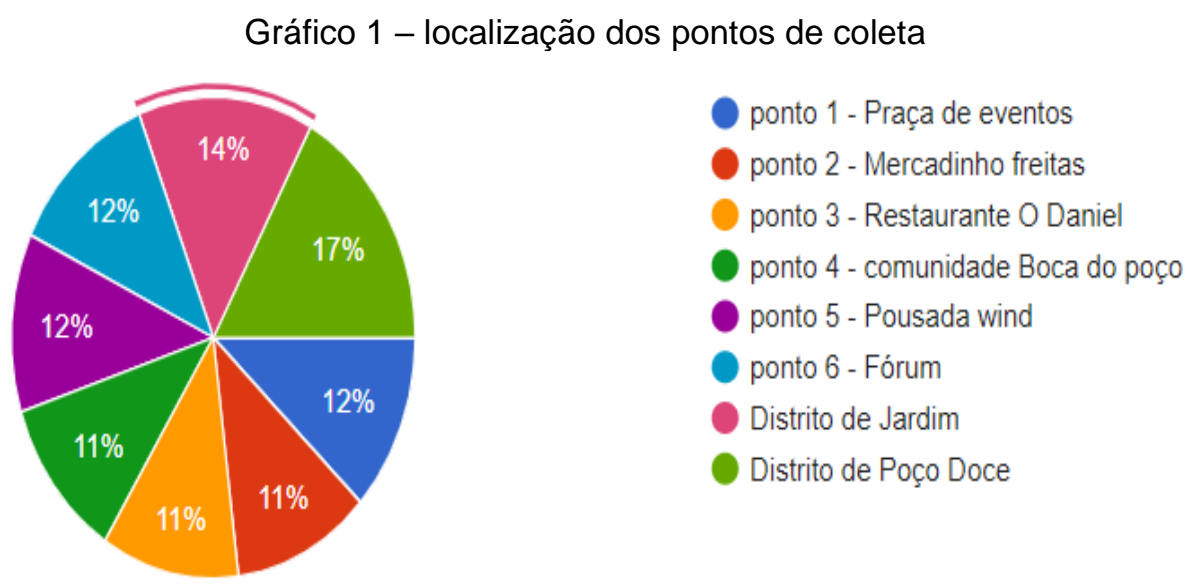

Fonte: Autores (2020).

Visando situar o leitor no que se refere a localização dos pontos de aplicação do questionário, o mapa abaixo (Mapa 2) apresenta a espacialização dos pontos.

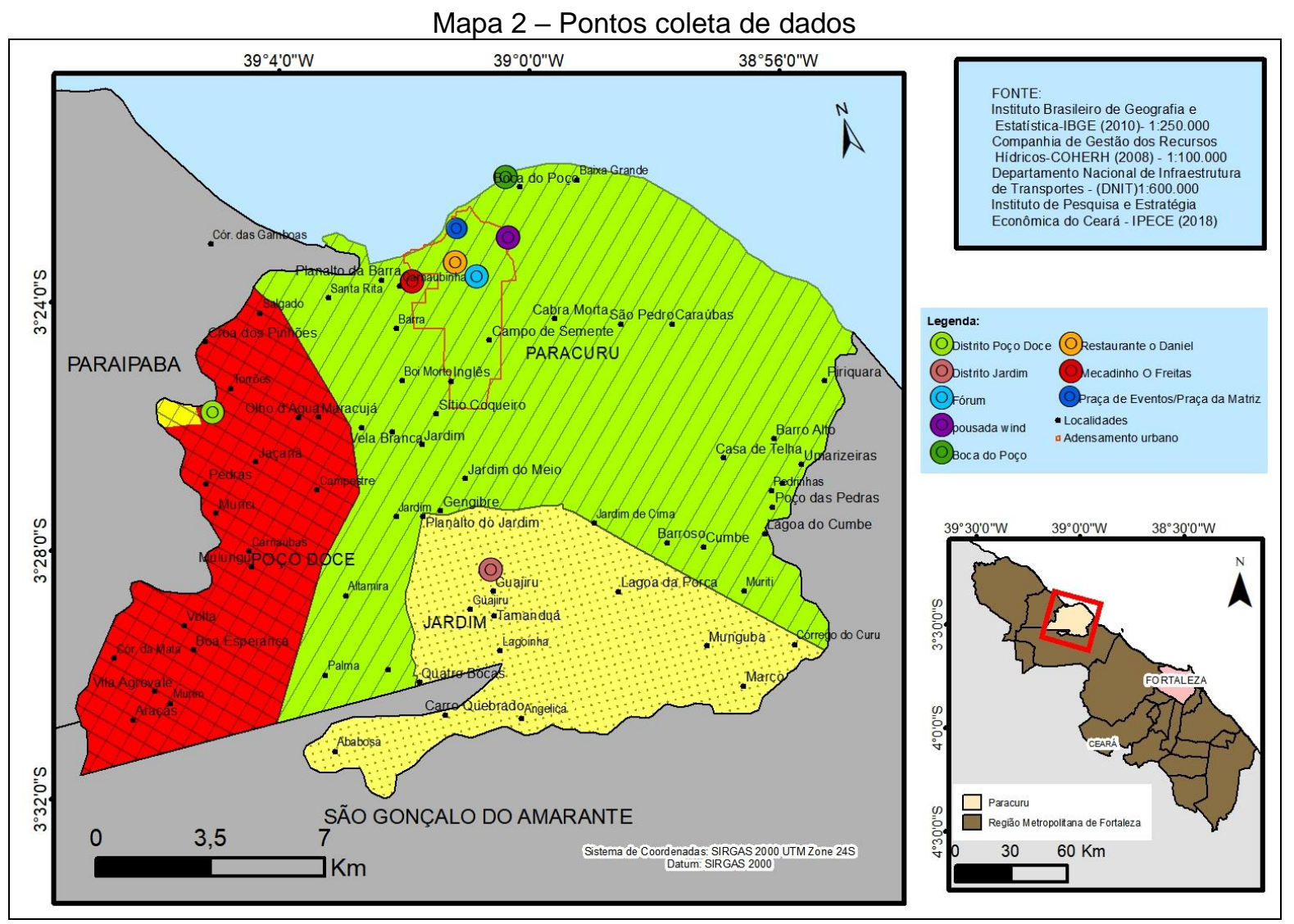

Fonte: Autores (2020).

Os pontos ilustram o local de início da coleta e localidades com maior concentração de residências no município de Paracuru. A maioria dos pontos de coleta está em Paracuru-sede, por razões logísticas o raio de deslocamento em cada ponto foi de até 3 quilômetros e nos distritos de Jardim e Poço Doce, onde predominam setores rurais o raio de deslocamento foi de até 5 quilômetros.

Aos moradores e Gestores foi aplicado o mesmo questionário com 11 perguntas, divididas em: perfil dos entrevistados; questões de identificação de problemas e possíveis soluções; e finalizando com questões voltadas especificamente à compreensão da vulnerabilidade e da qualidade ambiental, conforme é apresentado na imagem abaixo (Figura 2). Foi solicitado aos moradores a atribuição de notas aos

\begin{tabular}{llllll}
\hline Caminhos de Geografia & Uberlândia - MG & v. 22, n. 84 & dez/2021 & p. 101-118 & Página 105
\end{tabular}


ambientes das praias, manguezal, dunas, cidade e lagoas. Durante a pesquisa foi mencionado que a escala de 1 a 3 seria vulnerabilidade baixa ou muito baixa, 4 a 6 vulnerabilidade média, 7 a 8 vulnerabilidade alta, e 9 a 10 vulnerabilidade muito alta (escala elaborada pelos autores).

Figura 2 - Questionário aplicado aos moradores e gestores

\section{Questões relacionadas ao perfil do entrevistado.}

1. Qual o gênero ao qual você se identifica?

2. Qual a idade do colaborador?

3. Qual o grau de escolaridade que você possui?

4. Qual a sua profissão?

5. Como se denomina:

\section{Questões voltadas a identificação de problemas e possíveis soluções}

6. Quais os principais problemas (impactos socioambientais) você percebe no município de Paracuru?

7. Em sua opinião, qual o principal responsável pelo problema citado?

8. Quais sugestões você consegue apontar como possível solução aos problemas apontados?

\section{Questões voltadas especificamente à vulnerabilidade e a qualidade ambiental}

\section{Quais os ambientes mais vulneráveis?}

10. Em seu entendimento, quais as atividades econômicas exercem maior importância no Município?

11. De 1 a 10 como você avalia a qualidade ambiental da cidade de Paracuru?

Fonte: Autores (2020).

Para gestores foi aplicado o questionário em forma de entrevista mais elaborada, como detalha Minayo et al. (2005), foi realizada a pesquisa com o Secretário de Meio Ambiente em resposta a gestão municipal e com o Gestor das Unidades de Conservação Estaduais que representa a Secretaria de Meio Ambiente (SEMA). Aos gestores foi permitido que tivessem mais exposição das respostas para justificar de maneira mais demorada para melhor exposição das ideias.

\section{RESULTADOS, ANÁLISES E DISCUSSÕES}

De maneira geral, as questões relacionadas a percepção ambiental dos moradores do município de Paracuru apontaram que os agentes reconhecem a vulnerabilidade dos ambientes, sobretudo da cidade apresentada como sede urbana, bem como que o município em relação a qualidade ambiental precisa melhorar, tendo em vista a existência de inúmeros problemas. Já os gestores entrevistados apontaram que grande parte dos problemas pelos quais passa o município é resultante da dificuldade de gestão diante do cenário de descaso da classe política que não investe e não se interessa em equipar as secretarias.

Mediante a aplicação do questionário e a análise dos dados observou-se que o público feminino representou 51\% (51 entrevistados), e o masculino um percentual de $49 \%$ - 49 entrevistados. O que demonstra claramente que a pesquisa contou com um público constituído por ambos os sexos com bastante equilíbrio na amostra, como se observa no gráfico 2.

$\begin{array}{llllll}\text { Caminhos de Geografia } & \text { Uberlândia - MG } & \text { v. 22, n. } 84 & \text { dez/2021 } & \text { p. 101-118 } & \text { Página } 106\end{array}$


Gráfico 2 - Gênero dos entrevistados

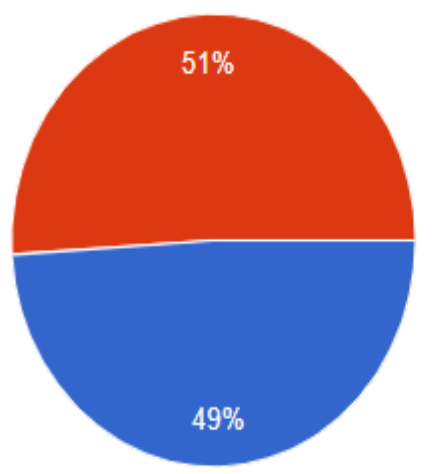

Masculino

Feminino

Fonte: Autores (2020).

O colaborador era a pessoa que em seu domicílio deu informações sobre o que foi questionado, e em alguns casos na impossibilidade do chefe de domicílio foi questionado a um dos membros da casa. A faixa etária do colaborador também apresentou homogeneidade, indicando que a amostra aleatória está válida.

Nesse sentido, ao fazer uma análise no que diz respeito ao nível de escolaridade dos colaboradores, verificou-se que $28 \%$ deles tinham entre 29 e 39 anos, enquanto 30\% estava na faixa etária de 51 ou mais. Na faixa etária de 18 a 28 anos foram $22 \%$, enquanto o menor público de colaboradores $20 \%$ representou o público-alvo com idade entre 40 a 50 anos (Gráfico 3).

Gráfico 3 - Faixa etária dos colaboradores

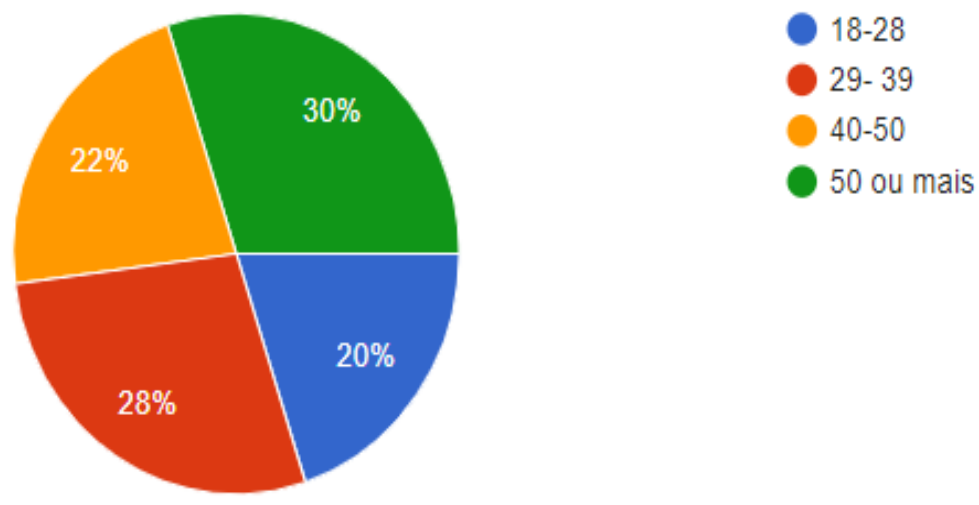

Fonte: Autores (2020)

Ainda no que se refere ao perfil dos colaboradores, a pesquisa quis identificar o nível de escolaridade dos mesmos. Mediante a análise dos dados, foi possível observar que a maior parcela de colaboradores, representada por $46 \%$, concluiu o Ensino Médio; outros $40 \%$ concluiram apenas o Ensino Fundamental e apenas 7\% afirmou ter cursado o Ensino Superior, esses 7\% com nível superior representam moradores itinerantes, o que evidencia que esse nível de ensino ainda é uma realidade para poucos. O cruzamento amostral de informações apontadas no gráfico 4 e 5 permite perceber que o público identificado como morador itinerante é o mesmo que possui ensino superior. A amostragem indicou ainda que outros $7 \%$ do público nunca frequentou a escola, a maior parte em função de depender do trabalho ou não tiveram acesso ao ensino na idade correta (Gráfico 4). 


\section{Gráfico 4 - Escolaridade concluída}

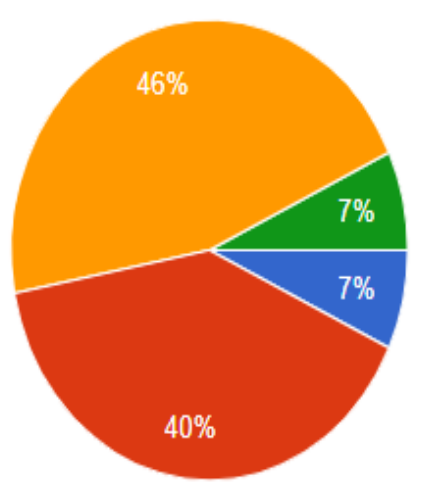

a) Nunca frequentou a escola;

b) Ensino Fundamental;

c) Ensino Médio;

d) Ensino Superior;

Fonte: Autores (2020).

O público-alvo dessa pesquisa foram os moradores com residência fixa e os moradores itinerantes, aqueles que por eventualidade de trabalho ou de outro motivo mantém residência em duas cidades. Nesse sentido, a pesquisa quis saber ainda se o morador residente da localidade ou pertencia a outro município e se o mesmo tinha o local como única residência. Para o caso de ele morar em mais de uma residência, foi questionado se é um morador itinerante ou apenas um turista.

De forma quase unânime, $92 \%$ dos colaboradores assumiram possuir uma única residência, enquanto $8 \%$ afirmaram uma relação de morador itinerante (Gráfico 5). Esse dado é importante, pois mais a frente se questionou sobre sua percepção a respeito de problemas e soluções, bem como características econômicas do município. De acordo com Casemiro et al. (2018), a opinião do morador local é importante, pois sendo ele conhecedor da realidade constitui um ator social, na medida em que lida diariamente com o meio ambiente local conhece o ambiente local melhor que outro que costuma passar apenas temporadas em determinada localidade.

Gráfico 5 - Referência do morador

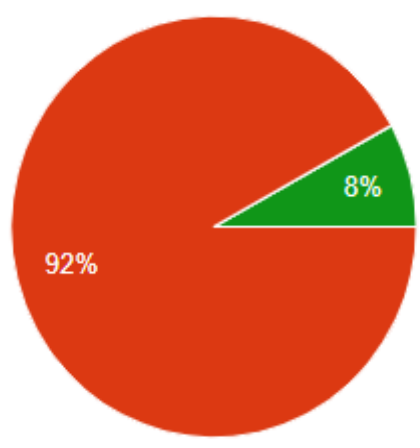

Turista
Morador
Mestor
Morador itinerante

Fonte: Autores (2020).

Os resultados apresentados na figura 9 fazem parte de uma mesma pergunta: quais os ambientes mais vulneráveis na percepção dos moradores? Em alguns casos a pergunta foi feita da seguinte maneira: quais os ambientes que na sua percepção necessitam de mais proteção? Principalmente quando os moradores não conseguiam entender o que era vulnerabilidade de risco e outros conceitos trabalhados na academia.

Os dados obtidos na questão relacionada a identificação dos ambientes mais vulneráveis na percepção dos moradores apontam que 42,4\% consideram a cidade como ambiente mais vulnerável; seguido das dunas $(35,4 \%)$, além de também considerarem muito alta a vulnerabilidade em praias $(31,3 \%)$, nas lagoas (30\%) e no manguezal (25\%). Apesar de esse último ser considerado berçário de muitas espécies, a riqueza desse ambiente é ainda desconhecida por parte da população.

$\begin{array}{llllll}\text { Caminhos de Geografia } & \text { Uberlândia - MG } & \text { v. 22, n. } 84 & \text { dez/2021 } & \text { p. 101-118 } & \text { Página } 108\end{array}$


No somatório da vulnerabilidade alta e muito alta, seguindo as notas 7, 8, 9 e 10 tem-se a cidade $68,7 \%$, dunas $52,6 \%$, praias $62,6 \%$, manguezal $55 \%$, lagoas $59 \%$. Para a percepção de média vulnerabilidade foram dadas notas entre 4 e 6 , onde tem-se: praias (20,7\%), manguezal (25\%), dunas $(31,3 \%)$, cidade $(21,1 \%)$, lagoas (28\%) (Gráfico 6).

\section{Gráfico 6 - Percepção dos moradores à vulnerabilidade}

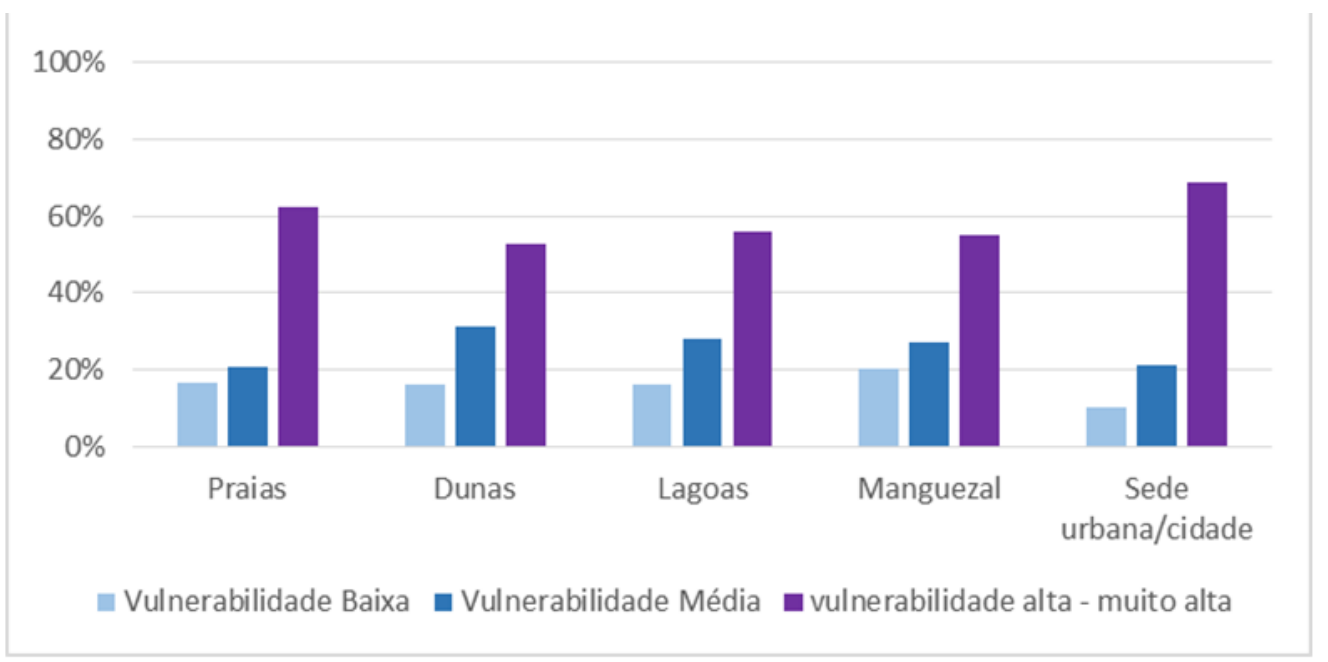

Fonte: Autores (2020).

Entendendo como baixa vulnerabilidade ou em outras palavras, os ambientes que menos precisam de proteção, a população que atribuiu notas entre 1 e 3, praias 16,6\%, manguezal 20\%, dunas $16,1 \%$, cidade $10,1 \%$, lagoas $16 \%$.

Com base nos dados, os moradores indicaram a cidade como mais vulnerável e o manguezal como menos vulnerável, além de indicar o conhecimento acerca dos riscos que existem no núcleo urbano principal ou desconhecimento acerca da importância dos manguezais, dunas e lagoas costeiras.

As informações obtidas reforçam que existe uma parcela da população que não reconhece os ambientes como áreas em que há a necessidade de proteção para uma convivência em hamonia, que mantenha a sustentabilidade. Entretanto, os moradores consideram que a cidade é o ambiente mais vulnerável, afirmando que a cidade é o local de moradia, comércio e das relações sociais, sendo necessário proteger para conter o avanço das dunas ou do mar.

A questão sobre o levantamento do diagnóstico das principais atividades econômicas foi inevitável, uma vez que as zonas costeiras são consideradas áreas estratégicas para diversos setores da vida social, política, meio ambiente e economia, e assim ser alvo de políticas públicas e investimento privado dos mais variados (Vasconcelos, 2005). Assim, foi solicitado ao morador a indicação de existência das atividades que em sua percepção exercem importância na economia do município de Paracuru; essa questão possibilitava ao entrevistado escolher mais de uma das alternativas.

Nesse sentido, as informações coletadas no que se refere as atividades desenvolvidas no município de Paracuru apontou um percentual de $80 \%$ dos moradores, destacando a atividade de comércio, $77 \%$ com indicações para pesca.

Outro conjunto de atividades muito citadas foi a agricultura, pecuária, silvicultura e exploração florestal, representado por 57\%. Já a contrução civil foi apontada por $52 \%$ deles; educação $51 \%$; saúde e serviços coletivos 44\%; alojamento e alimentação 39\%; a administração pública 36\%; as atividades imobiliárias, alugueis e serviços prestados a empresas representou 34\%; produção de eletricidade gás e água 30\%; serviços domésticos $30 \%$; outros serviços coletivos, sociais e pessoais $27 \%$, indústria de transformação $18 \%$ e os organismos internacionais e outras instituições extraterritoriais 6\% (Gráfico 7). 


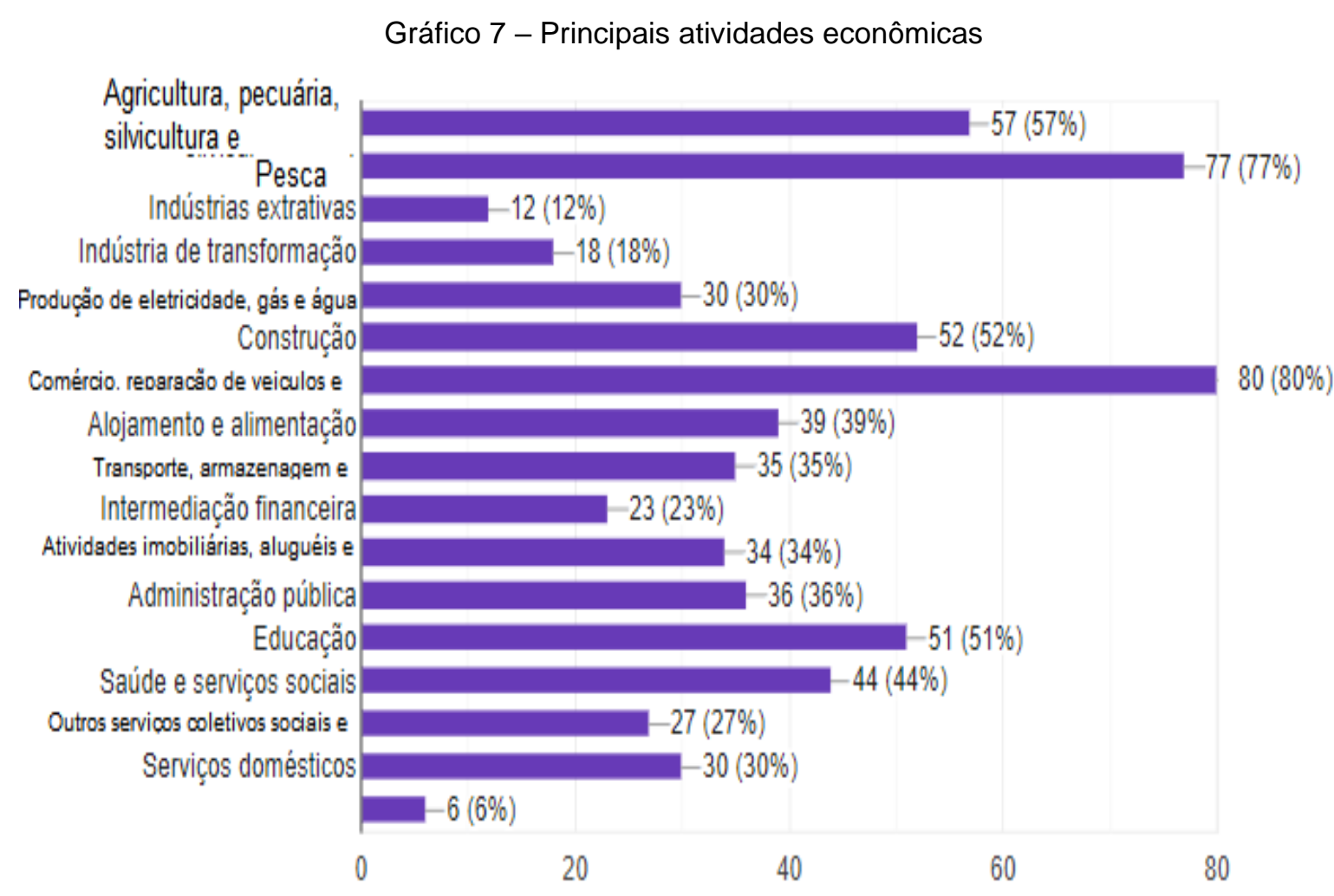

Fonte: Autores (2020).

Pode parecer confuso apontar tantas atividades em um município, porém há nele a presença de empresas nacionais e internacionais que trabalham com a extração de petróleo e produção de energia por meio de aerogeradores. Nos outros casos são atividades que um determinado grupo percebe e outro não, devido a sua concentração em uma área específica, por exemplo, quem mora mais próximo do rio menciona a extração de areia, já as pessoas que residem próximo da rodovia CE-341 indicaram a imobiliária e a construção civil como principal atividade. Os percentuais são relacionados à percepção do morador e não quer dizer que em dados oficiais as atividades econômicas sigam essa percepção, na verdade o setor que mais emprega é o de serviços, segundo a indústria, e em terceiro lugar a agropecuária.

$\mathrm{Na}$ questão seguinte também poderia ser apontado mais de uma alternativa visando a fornecer aos entrevistados uma maior liberdade e despertar a sua consciência. Nessa questão, solicitou-se deles indicar os principais problemas que vêm enfrentando. Pela observação dos dados (Gráfico 8), observa-se que $89 \%$ deles apontaram a má destinação do lixo encontrado nas ruas ou acumulado diante do atraso da coleta que é realizada com rodízio. $40 \%$ também responderam a poluição atmosférica, hídrica ou do solo. Sendo que do total, $39 \%$ apontaram como problema a presença de esgoto a céu aberto. 


\section{Gráfico 8 - Problemas ambientais percebidos}

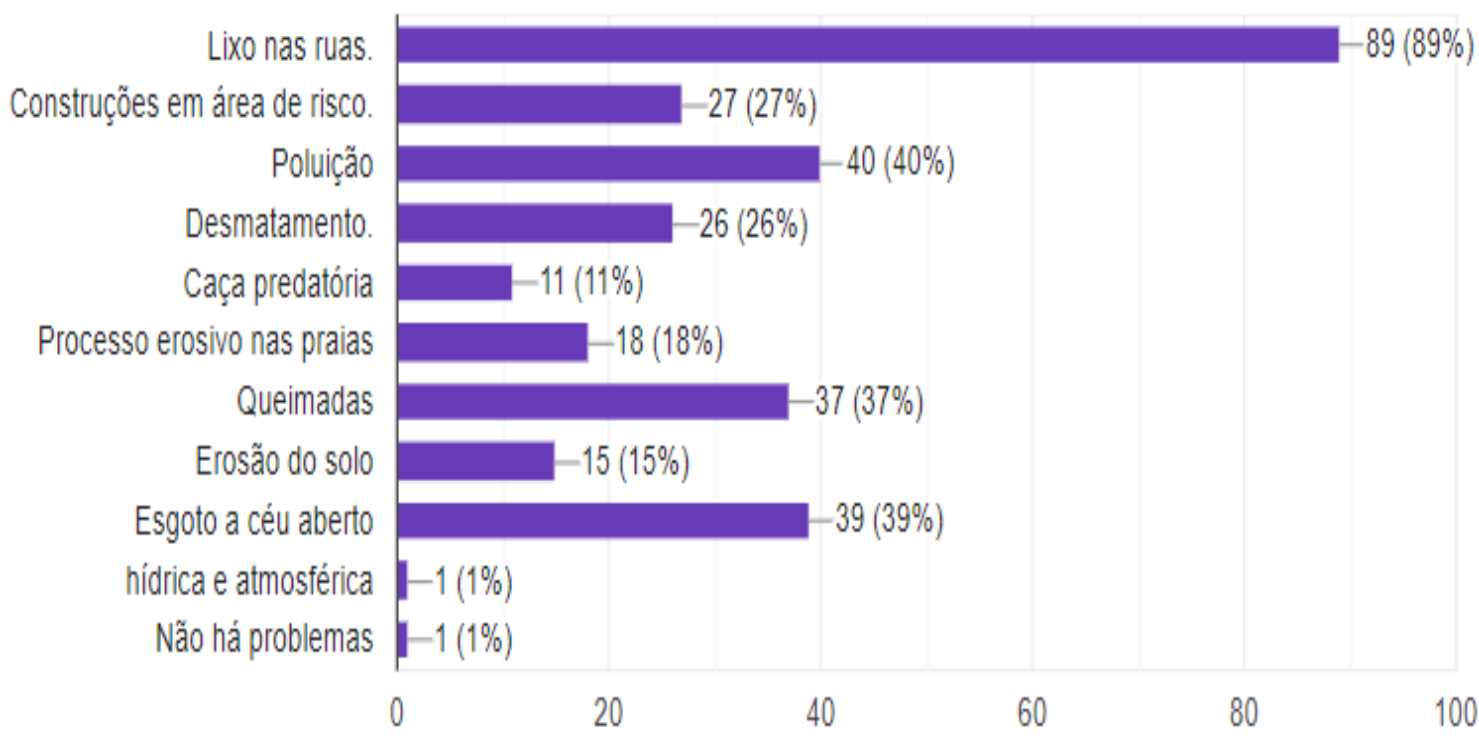

Fonte: Autores (2020).

Quando o assunto era as queimadas, 37\% consideraram que essa prática se dava nas áreas rurais para limpeza do terreno - replantio; porém, quando questionados sobre o desmatamento $26 \%$ afirmaram que perceberam alguma ação, principalmente nas proximidades do mangue com aerosão nos solos e nas praias percebidos por $15 \%$ e $18 \%$ respectivamente; enquanto isso $27 \%$ perceberam a existência de propriedades em área de risco, que é também um problema constatado e mencionado inclusive durante entrevista com gestores. Apenas $1 \%$ não percebeu nenhum problema a ser indicado, e 1\% afirmou haver poluição do tipo hídrica e atmosférica, mas sem especificar.

A pesquisa quis identificar ainda, na opinião dos entrevistados, quais seriam os principais agentes responsáveis pelos problemas por eles citados. A amostra espacializada no gráfico 9 revela que $69,4 \%$ apontaram que a população local é um dos responsáveis pelos problemas, em segundo lugar o próprio poder público seria o principal causador representado por $48 \%$, e $9,2 \%$ apontou como causa a urbanização mal planejada. No mais, vinculando a análise a períodos de gestões anteriores, $2 \%$ consideraram também a atividade turística desordenada. Vale acrescentar que nem todos responderam a essa questão, pois conforme a aprovação do Conselho de Ética, o morador deveria ficar a vontade para responder ou deixar de responder alguma questão.

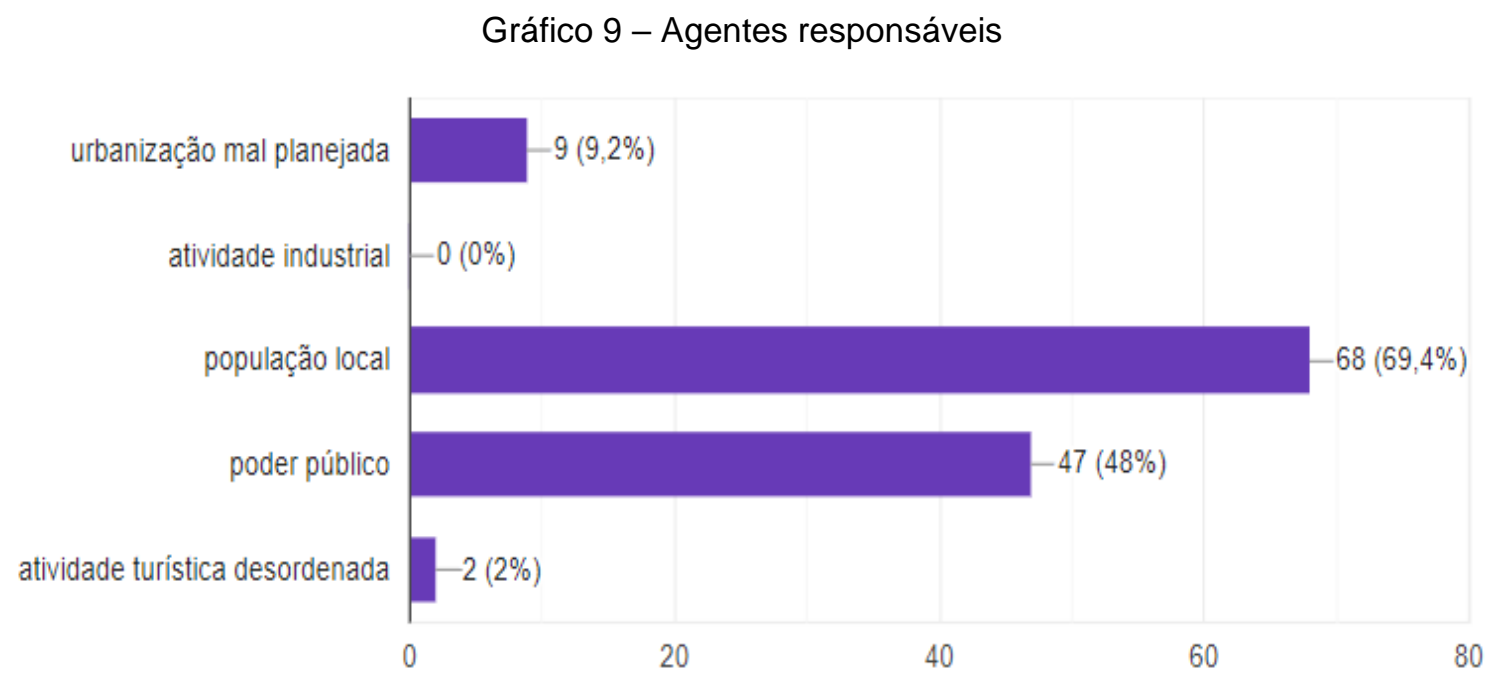

Fonte: Autores (2020). 
Os moradores indicaram que consideram a população como agente causador de alguns problemas apontando que ela se origina pela falta de conscientização ou quando há má vontade na vida cidadã, quando o morador não sabe que causa problema para os demais ou sabe e ainda assim age de má fé. Os colaboradores puderam apontar mais de um agente nesse caso, e o poder público foi bastante citado, por que é dele a competência para regular e fiscalizar. Quando isso não ocorre a culpa recai sobre a gestão.

A penúltima questão aplicada foi relacionada às sugestões que eles apontavam como forma de solucionar alguns dos problemas citados, a partir de uma grade de sugestões e com espaço para indicação em caso de não haver alternativa à sua resposta. Nessa alternativa eles também podiam indicar mais de uma sugestão percebida como válida para o problema apontado. Considerando que nem todos quiseram responder, cerca de $56 \%$ indicaram como solução a educação ambiental, pouco mais de $39 \%$ apontou a destinação de mais verba para fiscalização, $32 \%$ citou o planejamento participativo, $22 \%$ a mudança na legislação, e apenas $1 \%$ mencionou a necessidade de reestruturação do quadro político (Gráfico 10).

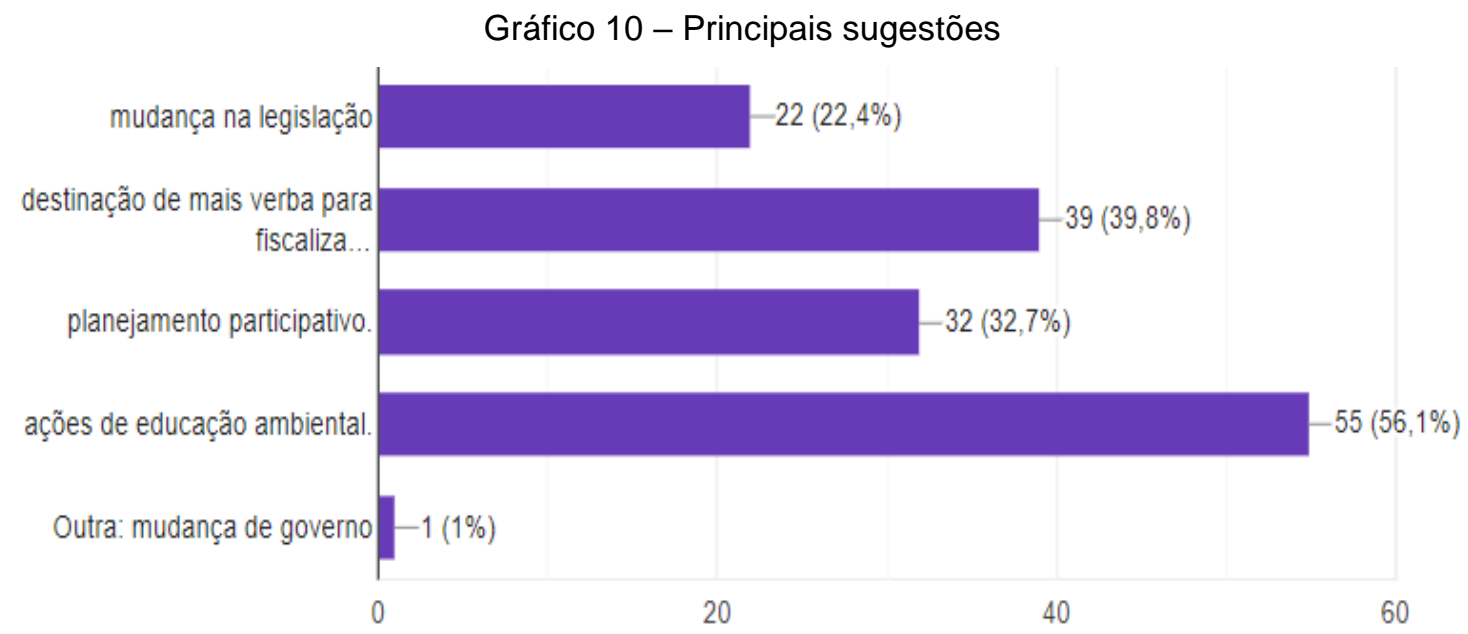

Fonte: Autores (2020).

A última questão foi relacionada especificamente a percepção da qualidade ambiental, ela destaca como os moradores enxergam a situação ambiental em Paracuru. Nessa questão foi solicitado dos colaboradores uma nota, considerando de 1 a 3 ruim ou péssima, 4 a 6 regular, 7 a 8 boa e 9 e 10 ótima.

Ao introduzir esse questionamento foi mencionado na pesquisa o conceito que poderia servir de base para a resposta do colaborador. Considerou-se para a análise o conceito de qualidade ambiental como conjunto de qualidades percebidas subjetivamente em aspectos de características como beleza e valor (Munn, 1979). Considerou-se ainda a percepção sobre a condição do ar, da água, do solo e dos ecossistemas em relação as ações humanas (Horberry, 1984).

De maneira geral, $10 \%$ dos moradores consideraram ótima a qualidade do ambiente, $38 \%$ apontou uma qualidade ambiental boa, $40 \%$ indicou média e $12 \%$ consideraram essa qualidade como ruim ou péssima. Os dados indicam haver a necessidade de melhorias ambientais, pelo menos para uma parcela da população amostral (Gráfico 11). 
Gráfico 11 - Percepção sobre a qualidade ambiental

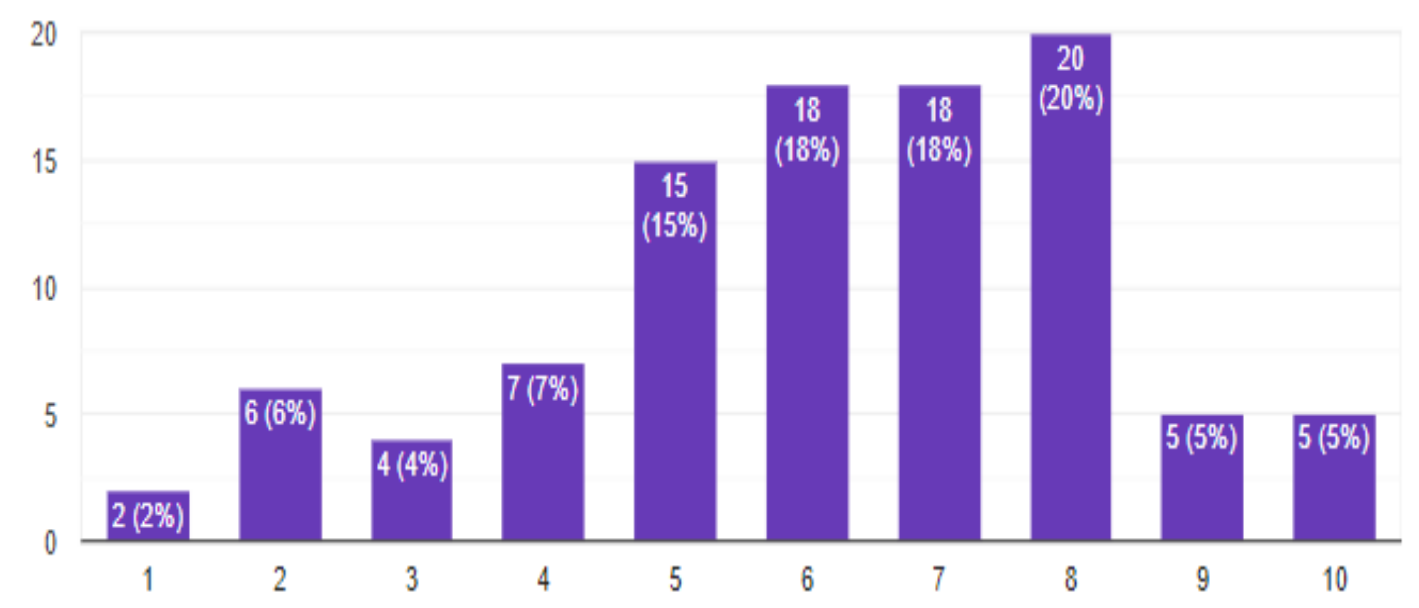

Fonte: Autores (2020).

Diante do exposto, percebe-se que há uma contradição ao que se refere a percepção da vulnerabilidade, tendo em vista que o percentual de moradores, que elencou o manguezal como mais vulnerável, foi inferior ao que elencou a cidade como mais vulnerável, indicando desconhecimento desse ecossistema tão importante. Fazendo uma correlação com os dados de escolaridade, provavelmente esse público é aquele que possui ensino superior e, portanto, um maior conhecimento da importância do manguezal. Referido planejamento não se objetivou/efetivou na prática, uma vez que os resultados esperados não conseguiram viabilizar as orientações elaboradas, de modo que as técnicas que foram propostas, apesar de aprovarem as medidas práticas indicadas, não conseguiram se concretizar no ordenamento efetivo da gestão da referida orla.

A pesquisa entrevistou ainda o gestor e o secretário municipal de Paracuru. As entrevistas foram realizadas com as mesmas perguntas do questionário de forma semiestruturada, seguindo um roteiro com possibilidade de perguntas específicas, porém com condições de respostas mais detalhadas e possibilidade de extensão de resposta citando documentos e a legislação vigente. Foram entrevistados o Secretário de Meio Ambiente de Paracuru e o gestor de duas Unidades de Conservação do município, a APA do Estuário do Rio Curu e a APA das dunas de Paracuru. Ambos são do sexo masculino, faixa etária entre $40-50$ e 29 - 40 anos respectivamente, e com Ensino Superior completo.

Para a gerência municipal são problemas: a má gestão de resíduos sólidos, a falta de fiscalização e o sucateamento dos órgãos públicos. Para o gestor das unidades de proteção são problemas ambientais: lixo acumulado em algumas ruas (Figura 3A); construções em áreas de risco (Figura 3B); poluição do solo e hídrica, desmatamento para a construção de empreendimentos (Figura 3C); queimadas (para agricultura ou ocupação, nas proximidades das UCs), problemas erosivos (Figura 3D), e esgoto a céu aberto (inclusive na faixa de praia). É possível encontrar evidências de um turismo desordenado, pois a administração do município não cumpre as leis, uma vez que não fiscaliza, porém é competência do município licenciar o território com exceção das unidades de conservação (Brasil, 2011). Outros problemas citados foram o avanço do campo de dunas e a pressão por carcinicultura sem licença. 
Figura 3 - Problemas identificados em Paracuru

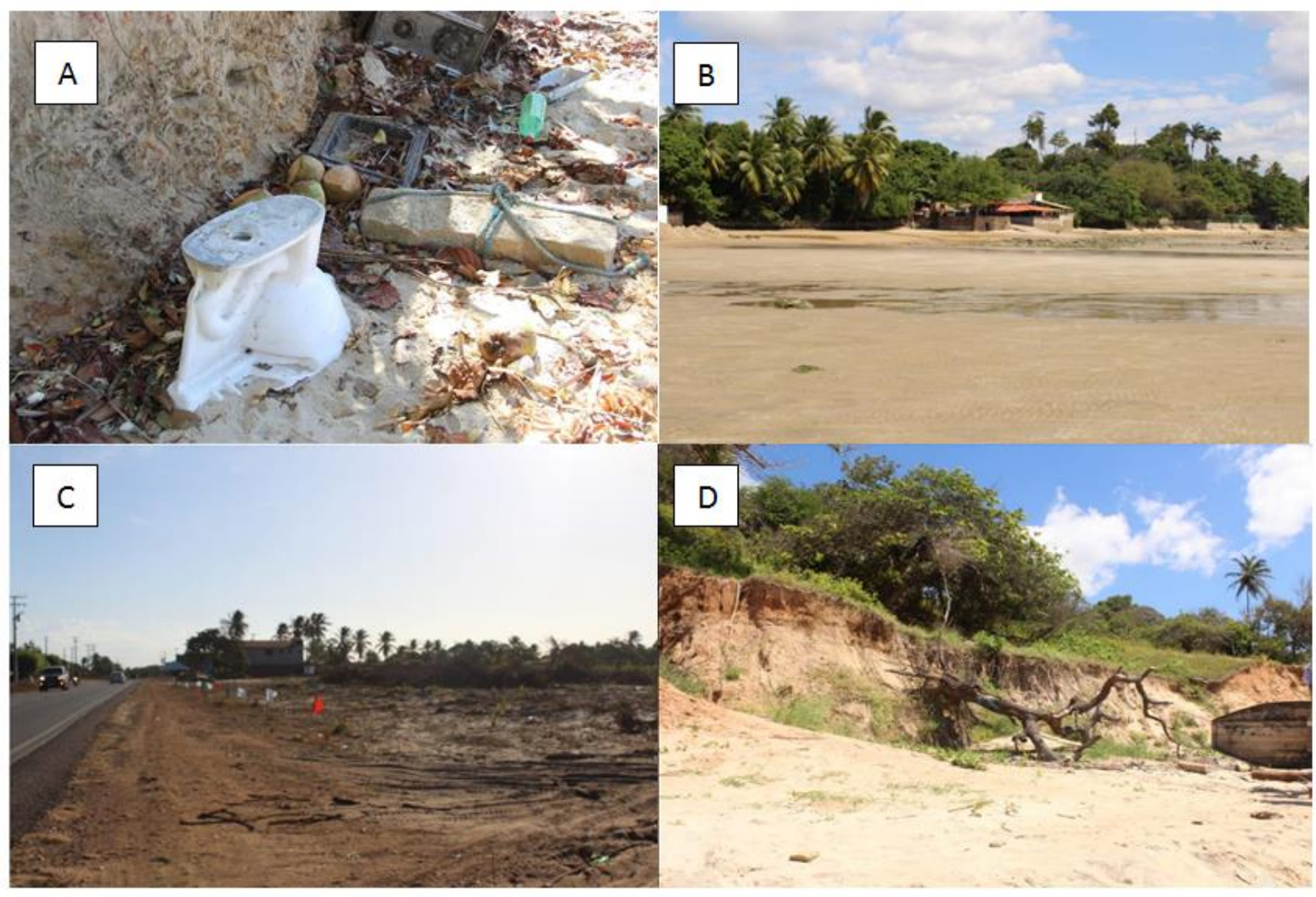

Fonte: Autores (2020).

O representante da secretaria municipal indicou como principais agentes responsáveis pelos problemas indicados o poder público e a população, à medida que não exercem poder de cobrar da classe política.

Para a gestão das APAS, quatro pontos foram elencados: urbanização mal planejada, população local, poder público e atividade turística desordenada.

Para solucionar os problemas, a gestão municipal pontuou mudança na legislação, destinação de mais verba para fiscalização, planejamento participativo, ações de educação ambiental e seguir a legislação local. Como solução o gestor das APAs (Estuário do Rio Curu e Dunas de Paracuru) citou mudança na legislação, planejamento participativo, ações de educação ambiental e reestruturação das secretárias do município (contratar mais pessoal qualificado).

Sobre a percepção dos ambientes mais vulneráveis, ambos atribuíram 10 para praias, manguezal, dunas, lagoas. Para o gestor das unidades, apenas a cidade não apresentava vulnerabilidade muito alta, e para o Secretário outro ambiente que poderia estar na classificação, embora de escala mundial seria o oceano, que também possuiria vulnerabilidade muito alta. Para o secretário municipal são pontos econômicos fortes no município: a pesca, construção, comércio e atividades imobiliárias.

O gerenciador das APAs corroborou com a afirmação do secretário municipal acrescentando como pontos fortes de atividades econômicas: agricultura, pecuária, silvicultura e exploração florestal, insdústria extrativista, alojamento e alimentação, administração pública, educação e saúde e serviços sociais.

Quanto a avaliação de qualidade ambiental, ambos deram a mesma nota 5 que representa qualidade regular, indicando que há necessidade de melhorias ambientais. Em resumo, as entrevistas foram satisfatórias, pois foi possível perceber a dificuldade da gestão diante de um cenário de descaso da classe política que não investe e não se interessa em equipar as secretarias e, embora haja gestão compartilhada, o limite da gestão estadual é a delimitação da APA do Estuário do Rio Curu e da APA das Dunas (Mapa 3), pois ambos os representantes da gestão percebem que nem todos os

$\begin{array}{llllll}\text { Caminhos de Geografia } & \text { Uberlândia - MG } & \text { v. 22, n. } 84 & \text { dez/2021 } & \text { p. 101-118 } & \text { Página } 114\end{array}$


Análise da percepção ambiental como subsídio à gestão no município de Paracuru - CE

Cristiano da Silva Rocha

ambientes suportam a ocupação desordenada, e que há necessidade de melhorar as condições ambientais.

Mapa 3 - Mapa das Áreas de Proteção Ambiental em Paracuru - Ceará

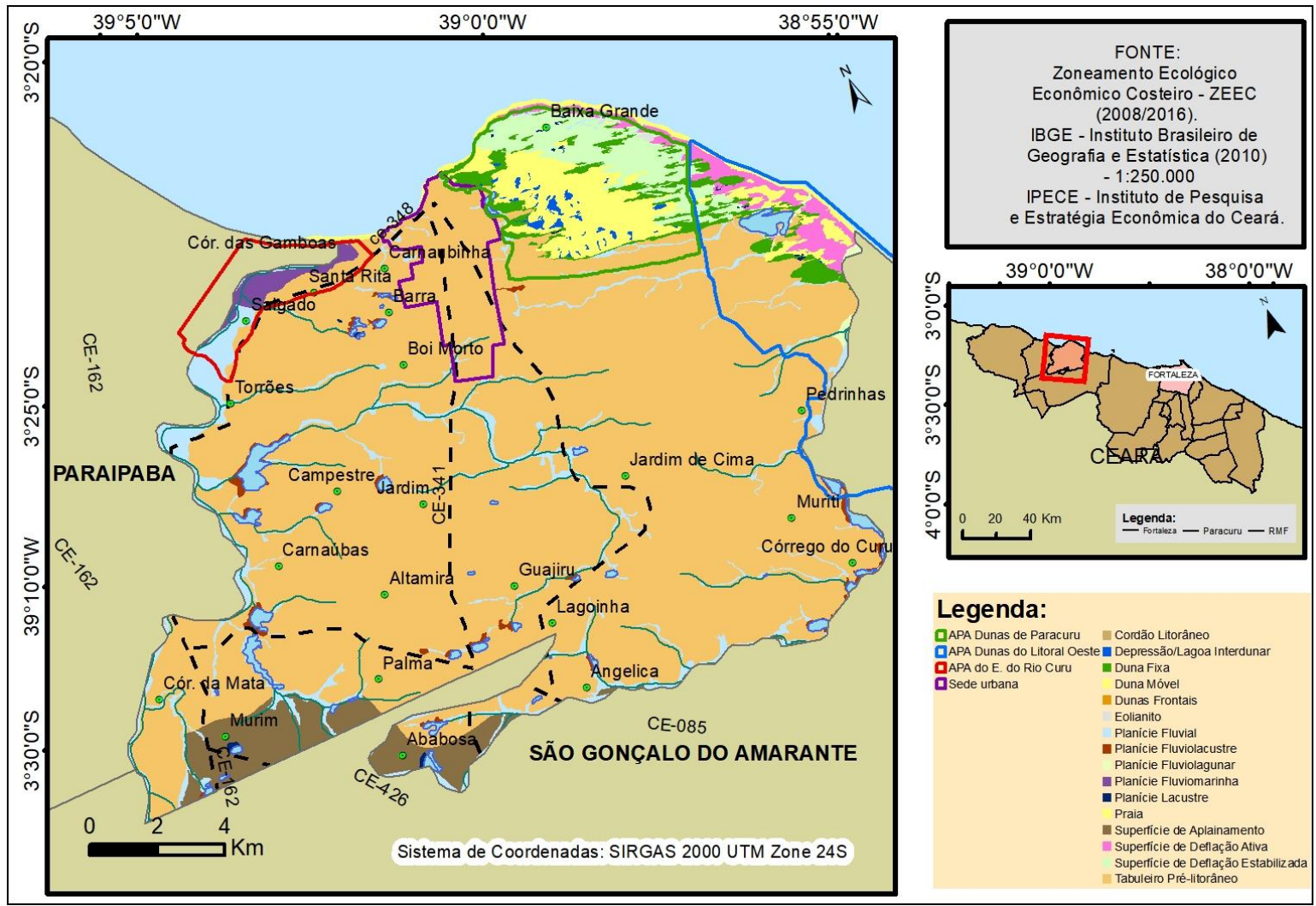

Fonte: Autores (2020).

Foi mencionado na entrevista que o município solicitou o Projeto Orla, mas não deu continuidade, pois não apresentou o Projeto de Gestão Integrada (PGI), e em muitos casos o interesse do município se dá pela verba e pela política de cooperação que permite o município tomar as decisões de seu próprio gerenciamento, inclusive licenciando obras. Entretanto, essa maneira de cooperação não é adquirida exclusivamente pelo Projeto Orla. No caso de Paracuru, o gerenciamento é realizado pela prefeitura em parceria com o Estado, visto que ao município cabe a fiscalização e licenciamento de seu território, inclusive dos terrenos de marinha, com exceção das unidades de conservação, que são de competência do Estado, que executa por meio da SEMACE.

Historicamente, os projetos e a legislação que geralmente regulamentam o uso e ocupação do solo de Paracuru - a exemplo do Projeto Orla e da Lei complementar N. 140/2011, foram implementados de maneira tardia, e os objetivos que são colocados para licenciamento são cumpridos de forma precária, pois para a fiscalização faltam recursos, veículos, diárias e pessoal qualificado. Em suma, há legislação local por meio do plano diretor - que é um dos critérios citados - porém, não há cumprimento integral da lei municipal.

Em conclusão, entende-se que a discussão aqui apresentada sobre a vulnerabilidade social e socioambiental pode dar base para o planejamento ambiental, tão necessário a sustentabilidade, ao indicar áreas mais suscetíveis com baixa capacidade de resiliência que necessitam de mais proteção. Outro ponto de discussão realizado diz respeito ao detalhamento da percepção ambiental por meio dos dados dos questionários indicando problemas ambientais e caminhos a serem percorridos como forma de soluções. Com base nesta síntese, é possível apontar uma proposta como um canal participativo a nível local, fornecendo a possibilidade de feedback da população.

\section{CONSIDERAÇÕES FINAIS}


Em Paracuru, as informações encontradas revelam que a maioria dos colaboradores vivencia e conhece o município, e por isso mostram um posicionamento crítico em relação aos problemas e a vulnerabilidade dos ambientes. Entretanto, quando identificadas as respostas em relação a percepção de quais ambientes menos vulneráveis ou quais ambientes necessitariam menos de proteção, medido pelas notas de 1 a 3 , aparecem manguezal, praias e dunas em destaque, com 20\%, 16,7\% e 16,1\% respectivamente. Somando-se a isso, os moradores percebem a cidade ambiente de convívio mais vulnerável. De maneira geral, as principais considerações obtidas a partir da pesquisa foram:

- $\quad$ Com base na pesquisa moradores e gestores percebem problemas ambientais, entretanto, não há mobilização social ou reação de enfrentamento;

- Os problemas mais citados foram aqueles que estão mais próximos da realidade dos moradores, tais como: atraso ou ausência da coleta seletiva de lixo, poluição e esgoto a céu aberto. Isso não quer dizer que o processo erosivo nas praias que foi apontado por Rocha (2020) não tenha sido percebido. Notou-se que as pessoas que residem nos distritos mais afastados não percebem problemas erosivos nas praias devido ao baixo interesse em frequentá-los.

A população local e o poder público foram citados como principais agentes causadores dos problemas, revelando necessidade de diálogo e cooperação entre as partes;

- De maneira geral, os agentes que cederam as respostas confirmaram que reconhecem a vulnerabilidade dos ambientes, sobretudo da cidade apresentada como sede urbana, e que o município em relação a qualidade ambiental precisa melhorar;

- Sobre a percepção da vulnerabilidade, o percentual de moradores que elencou manguezal como vulnerabilidade alta e muito alta foi inferior ao que elencou a cidade como mais vulnerável, indicando desconhecimento desse ecossistema tão importante para regulação ambiental.

- $\quad \mathrm{Na}$ percepção dos gestores, há reconhecimento dos problemas citados pelos moradores acrescentando-se a pressão por carcinicultura ilegal, e indicando também, em relação a gestão falta de incentivo a fiscalização pela ausência de equipamentos e pressão política.

- Os gestores citaram ainda problemas no cumprimento da legislação, principalmente a nível municipal, que possui Plano Diretor, mas com base na entrevista não é cumprido. Soma-se a isso o fato que alguns dos critérios para o município licenciar seu território são a legislação específica e possuir equipe técnica multidisciplinar, indicando o cumprimento de critérios de maneira precária.

Em síntese, com base nas considerações é possivel afirmar que o caminho para a cooperação entre os atores sociais é a interdisciplinaridade, que consegue capturar o olhar sobre o local dialogando entre as especificidades ambientais e sociais, tentando contribuir para os próximos passos diante um cenário futuro e incerto, marcado pela ignorância e falta de reconhecimento de que somos seres dependentes da natureza. Por meio do trabalho, os subsídios lançados podem ser aplicados às prioridades do município e na maneira de gerir ambientes, justificando a impossibilidade de ocupação de algumas áreas. Portanto, diante de um horizonte em que o município licencia e muitos critérios têm cumprimento de requisitos de forma precária, é ainda maior a necessidade de participação popular na fiscalização e cobrança de melhorias sociais e ambientais.

\section{REFERÊNCIAS}

BRASIL. Ministério do Meio Ambiente. Lei complementar n. 140, de 8 de dezembro de 2011. Fixa normas, nos termos dos incisos III, VI e VII do caput e do parágrafo único do art. 23 da Constituição Federal, para a cooperação entre a União, os Estados, o Distrito Federal e os Municípios e dá outras providências. Diário Oficial da União. Disponível em: http://www.planalto.gov.br/ccivil03/LEIS/LCP/Lcp140.htm. Acesso em: 05 mar. 2020.

CASEMIRO, M. B.; BARRA, O. A. O. L.; VASCONCELOS, F. P.; MATOS, F. O. Análise do Projeto Orla Marítima de Icapuí/CE na perspectiva dos gestores locais e ambientalistas. Caminhos de Geografia, Uberlândia, v. 19, n. 66, p. 361-374, 2018.

$\begin{array}{llllll}\text { Caminhos de Geografia } & \text { Uberlândia - MG } & \text { v. 22, n. } 84 & \text { dez/2021 } & \text { p. 101-118 } & \text { Página } 116\end{array}$


CAVALCANTE, A. L.; SULIANO, D.; PAIVA, W. L.; TROMPIERI NETO, N.; LIMA, C.; SOARES, R. Indicadores Econômicos do Ceará - 2017. IPECE, 2017. Fortaleza - CE. Disponível em: https://www.ipece.ce.gov.br/wpcontent/uploads/sites/45/2019/02/Indicadores Economicos 2013 a 2017. pdf. Acesso em: 05 jun. 2019.

CEARÁ. Secretaria Estadual do Meio Ambiente. Lei complementar n. 180, de 19 de julho de 2018, dispõe sobre o Programa de Governança Inter federativa do estado do Ceará, denominado "Ceará um só". Diário Oficial do Estado, Fortaleza-Ceará. Disponível em:

https://www.jusbrasil.com.br/diarios/199897272/doece-19-07-2018-pg-10. Acesso em: 11 jul. 2020.

CEARÁ. Superintendência Estadual do Meio Ambiente. Reestruturação e atualização do mapeamento do projeto Zoneamento Ecológico-Econômico do Ceará - zona costeira e unidades de conservação costeiras. Fortaleza: SEMACE, 2016.

CHAER, G.; DINIZ, R. R. P.; RIBEIRO, E. A. A técnica do questionário na pesquisa educacional. Evidência, Araxá, v. 7, n. 7, p. 251-266, 2011.

CEPAL. Comissão Econômica para a América Latina. Vulnerabilidade Sociodemográfica: viejos y nuevos riesgos para comunidades, hogares e personas. Brasília: CEPAL/ECLAC, 2002.

FERNANDES, L. G.; SANSOLO, D. G. Percepção ambiental dos moradores da cidade de São Vicente sobre os resíduos sólidos na Praia do Gonzaguinha, SP, Brasil. Revista da Gestão Costeira Integrada [online], v. 13, n. 3, p. 379-389, 2013. Disponível em: https://www.aprh.pt/rgci/pdf/rgci-416 Fernandes.pdf. Acesso em: 19 jan.2020.

HILL, M. M.; HILL, A. B. A Construção de um Questionário. Lisboa: Dinâmica Editora, 1998.

HORBERRY, J. A. J. Development Assistance and the Environment. Dissertation, Massachusetts Institute of Technology. Cambridge, Massachusetts. 1984.

IBGE. Instituto Brasileiro de Geografia e Estatística. Censo demográfico - 2010. Características da população e dos domicílios: resultados do universo. Rio de Janeiro: IBGE, 2010. Disponível em: https://www.ibge.gov.br/. Acesso em: 15 mar. 2020.

IBGE. Instituto Brasileiro de Geografia e Estatística. Estimativa populacional - 2020. Rio de Janeiro: IBGE, 2020. Disponível em: https://cidades.ibge.gov.br/brasil/ce/paracuru/panorama. Acesso em: 22 jul. 2021.

LEVINE, D. M.; BERENSON, M. L.; STEPHAN, D. Estatística: Teoria e Aplicações usando Microsoft Excel em Português. Rio de Janeiro: LTC, 2000.

MACEDO, R.L.G. Percepção e Conscientização Ambientais. Lavras: FAEPE, 2000.

MEDEIROS, E. C. S.; PANTALENA, A. F.; MIOLA, B.; LIMA, R. S.; SOARES, M. O. Percepção ambiental da erosão costeira em uma praia no litoral do Nordeste do Brasil (Praia da Taíba, CE). Journal of integrated coastal zone management, v. 14, n. 3, p. 471-482, 2014. Disponível em: $<$ http://www.scielo.mec.pt/pdf/rgci/v14n3/v14n3a09.pdf. Acesso em: 10 jul. 2020

MINAYO, M. C. S. O desafio do conhecimento: pesquisa qualitativa em saúde. São Paulo: Hucitec/ABRASCO, 1992.

MINAYO, M. C. S.; ASSIS, S. G.; SOUZA, E. R. Avaliação por triangulação de métodos: Abordagem de Programas Sociais. Rio de Janeiro: Editora Fiocruz, 2005.

MUNN, R. E. Enviromental impact assement, England: SCOPE, 1979.

PALMA, I. R. Análise da percepção ambiental como instrumento ao planejamento da educação ambiental. 2005. Dissertação (Mestrado em Engenharia). Escola de Engenharia da Universidade Federal do Rio Grande do Sul - UFRGS, Porto Alegre, 2005. Disponível em: https://lume.ufrgs.br/handle/10183/7708. Acesso em: 20 de abr. 2020.

PAULA, E. M. S.; SILVA, E. V. da; GORAYEB, A. Percepção ambiental e dinâmica geoecológica: Premissas para o planejamento e gestão ambiental. Sociedade e Natureza, Uberlândia, v. 26, n. 3, p. 511-518, 2014. Disponível em: https://www.scielo.br/j/sn/a/CtMb6KGTgcmbCfkSQPyFTtG/?lang=pt\&format=pdf. Acesso em: 10 jul. 2020. 
PACHECO, E.; SILVA, H. P. Compromissos epistemológicos do conceito de percepção ambiental. Rio de Janeiro: Programa EICOS/UFRJ, 2006. Disponível em: https://docplayer.com.br/51002179189\%20Compromissos-epistemologicos-do-conceito-de-percepcao-ambiental.html.. Acesso em: 11 maio 2020.

ROCHA, C. S. Análise socioambiental como subsídio à gestão integrada da zona costeira em Paracuru - CE. 2020. 219 f. Dissertação (Mestrado Acadêmico em Geografia), Universidade Estadual do Ceará, Fortaleza, 2020. Disponível em:

<http://www.uece.br/mag/dmdocuments/cristianoda silva rocha.pdf>. Acesso em: 03 jul. 2020.

ROSSONI, H. A. V.; FARIA, M. T. S.; ROSSONI, F. F. P.; PASSOS, M. O.; FARIA, B. R. N.; LEMOS, C. F. Análise da percepção ambiental da cidade universitária de Florestal, Minas Gerais - Brasil. Caminhos de Geografia, v. 13, n. 41, p. 240-25, 2012.

SANTOS, T. C. C.; CÂMARA, J. B. D. (Orgs.). Perspectivas do Meio Ambiente no Brasil. Brasilia: edições IBAMA, 2002.

SOUZA, L. B.; ZANELLA, M. E. Percepção de riscos ambientais: teoria e aplicações. Edições UFC: Fortaleza, 2009.

SOUZA, M. J. N. de; OLIVEIRA, V. P. V. de; GRANJEIRO, C. M. M. Análise geoambiental. In: ELIAS, D. 0 Novo Espaço da Produção Globalizada: O Baixo Jaguaribe-CE. Fortaleza: FUNECE, 2002.

SCHIAVINATO, V. M. S.; GONZÁLEZ, A. Z. D. Degradação de áreas de nascentes na sub-bacia hidrográfica do córrego das Pitas-MT: O que pensam os pequenos produtores rurais? Caminhos de Geografia. Uberlândia-MG, v. 21, n. 74, p. 295-312, 2020.

TRICART, J. Ecodinâmica. Rio de Janeiro: IBGE/SUPREN, 1977.

VASCONCELOS, F. P. Gestão Integrada da Zona Costeira: Ocupação antrópica desordenada, erosão, assoreamento e poluição ambiental do litoral. Fortaleza: Premius, 2005.

WHYTE, A. La perception de L'environnement: lignes directrices méthodologiques pour les études sur le terrain. Notes techniques du MAB 5. Paris: UNESCO. 1978.

Recebido em: 15/08/2020

Aceito para publicação em: 28/07/2021 